Haya: The Saudi Journal of Life Sciences

Abbreviated Key Title: Haya Saudi J Life Sci

ISSN 2415-623X (Print) |ISSN 2415-6221 (Online)

Scholars Middle East Publishers, Dubai, United Arab Emirates

Journal homepage: https://saudijournals.com

Review Article

\title{
Role of Potential Compounds in Foods with Particular Emphasizes on Human Health
} \author{
Javed $^{3}$, Alyan Ashraf ${ }^{4}$, Abid Hussain \\ ${ }^{1}$ College of Food Science and Technology, Huazhong Agricultural University, China \\ ${ }^{2}$ Institute of Food Science and Nutrition, Bahauddin Zakariya University, Multan, Pakistan \\ ${ }^{3}$ Departemnt of Food Engineering, University of Agriculture, Faisalabad, Pakistan \\ ${ }^{4}$ Centre of Agricultural Biochemistry and Biotechnology (CABB), University of Agriculture Faisalabad, Pakistan \\ ${ }^{5}$ Department of Agronomy, University of Agriculture, Faisalabad, Pakistan
}

Muhammad Burhan Khan Tareen ${ }^{1 *}$, Sheeraz Ahmad Khan ${ }^{2}$, Muhammad Bilal Rana ${ }^{2}$, Sahar Haq ${ }^{2}$, Muhammad Saqib

DOI: $\underline{10.36348 / \mathrm{sj} 1 \mathrm{l} .2020 . \mathrm{v} 05 \mathrm{i} 12.004}$

| Received: 08.11.2020 | Accepted: 19.11.2020 | Published: 10.12.2020

*Corresponding author: Muhammad Burhan Khan Tareen

\section{Abstract}

Human nutrition is the process by which substances in food are transformed into body tissues and provide energy for the full range of physical and mental activities that make up human life. Antioxidants that usually taken through diet and have an important role in inhibition of stress due to oxidation that reason for beginning and development of numerous diseases such as cancer, and much other disease such as diabetes and also inflammation. There are certain gaps in literature about the different activities in compounds that exhibit functions in vegetables and fruits. Different free radical leads to oxidative stress to the particular cell and ultimately causes the cancer. The natural phenolic compounds have received increasing interest in the last years, since a great amount of them can be found in plants and consumption of vegetables and beverages with a high level of such compounds may reduce the risk of development of several diseases due to their antioxidant power, among other factors. Kaempferol as one of the flavonoids that main function involved in binding with cells of the cancer and ultimately kills the cancer cells. Anthocyanin mainly the type of the major compound in the outer portion of the skin of the onions The colour of the red showing the activities against the free radicals depending on the type as well as the nature of the chemical compound. Quercetin as the valuable type of the flavonoids that have been used in the purpose of the preventing diseases associated with the bacteria as well as the viruses. Different free radical leads to oxidative stress to the particular cell and ultimately causes the cancer.

Keywords: Human Nutrition, Foods, Biotechnological applications, cancer, antioxidants.

Copyright (C) 2020 The Author(s): This is an open-access article distributed under the terms of the Creative Commons Attribution 4.0 International License (CC BY-NC 4.0) which permits unrestricted use, distribution, and reproduction in any medium for non-commercial use provided the original author and source are credited.

\section{INTRODUCTION}

Carbohydrate, fat, and protein are, to a large extent, interchangeable as sources of energy. Typically, the energy provided by food is measured in kilocalories, or Calories. One kilocalorie is equal to 1,000 gramcalories (or small calories), a measure of heat energy. However, in common parlance, kilocalories are referred to as "calories." In other words, a 2,000-calorie diet actually has 2,000 kilocalories of potential energy. One kilocalorie is the amount of heat energy required to raise one kilogram of water from 14.5 to $15.5{ }^{\circ} \mathrm{C}$ at one atmosphere of pressure. Another unit of energy widely used is the joule, which measures energy in terms of mechanical work. Throughout most of the world, protein supplies between 8 and 16 percent of the energy in the diet, although there are wide variations in the proportions of fat and carbohydrate in different populations [1].

Human nutrition deals with the provision of essential nutrients in food that are necessary to support human life and good health. Poor nutrition is a chronic problem often linked to poverty, food security or a poor understanding of nutrition and dietary practices and poor knowledge about nutrients required by the body at various stages of life to prevent deficiency of nutrients in body which can have adverse effects on body [2,3]. Malnutrition and its consequences are large contributors to deaths, physical deformities and disabilities worldwide [4]. Good nutrition is necessary for children to grow physically and mentally, and for normal human biological development [5]. 
Quercetin is a strong antioxidant found in many plants and it is widely used in dietary supplements. Bacteria Bacillus cereus transformed quercetin to isoquercetin (quercetin 3-Oglucopyranoside) with $20.0 \%$ yield. Whereas, fungus B. bassiana ATCC 7159 transformed quercetin to quercetin 7-O- $\beta$-D-(4"'-O-methyl)-glucopyranoside with $87.0 \%$ yield, and Cunninghamella elegans ATCC 9245 to quercetin 3-O- $\beta$-D-glucopyranoside with $55.7 \%$ yield transformation of quercetin and its glycosides due to metabolism by intestinal bacteria[6].

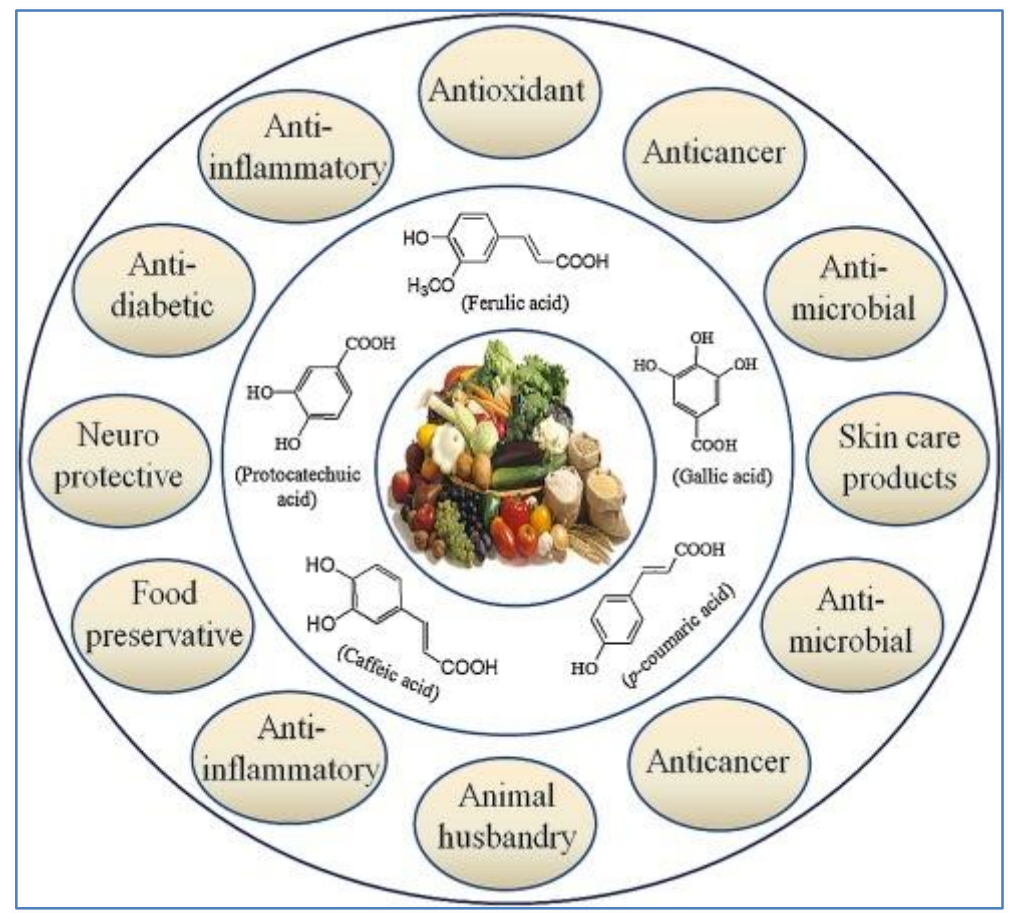

Fig-1: Shows the Foods with natural compounds against diseases

There are certain gaps in literature about the different activities of the extracts of the onion. The antioxidant activity of the onion extract remains unclear and not completely studied yet. Different free radical leads to oxidative stress to the particular cell and ultimately causes the cancer. The further study needed to understand the nature of different chemical compounds in onion that responsible for antioxidant activity as well as for the different routes for entry of free radicals into the living.

\section{Antioxidant activity}

Red the type of onions displaying maximum effect of DPPH scavenging as compared to other types of onions that are less scavenging ability. The assay in relation to DPPH indicated that for comparison of onions with higher concentrations of anthocyanin as well as quercetin has a tendency to display high power of antioxidant. A study showed that using of onion that red in colour leads to enhance plasma level and also their activity of enzymes such as superoxide dismutase also glutathione peroxidase with the decreases in concentration of malondialdehyde that found in cells of liver [7].

Previous study on the onion showed that extracted obtained from onion contained the polysaccharide displaying activity against oxidants called antioxidant activity towards ABTS that commonly used in the assay linked to enzymes that function to bind cations, and also scavenging of the radicals of superoxide anion. Some of the recent research related to the compounds found in onions showed that onions possess the compounds with great potential among the all major plants that majorly used to treat the disease such diabetes, cancer. Onions also showing the activity against the free radicals. Lots of ways existed to inhibit the mechanism of the oxidants during metabolism. The cellular level ultimately caused the formation of the free radicals due to the more level of oxidants in the specific cell [8]. 


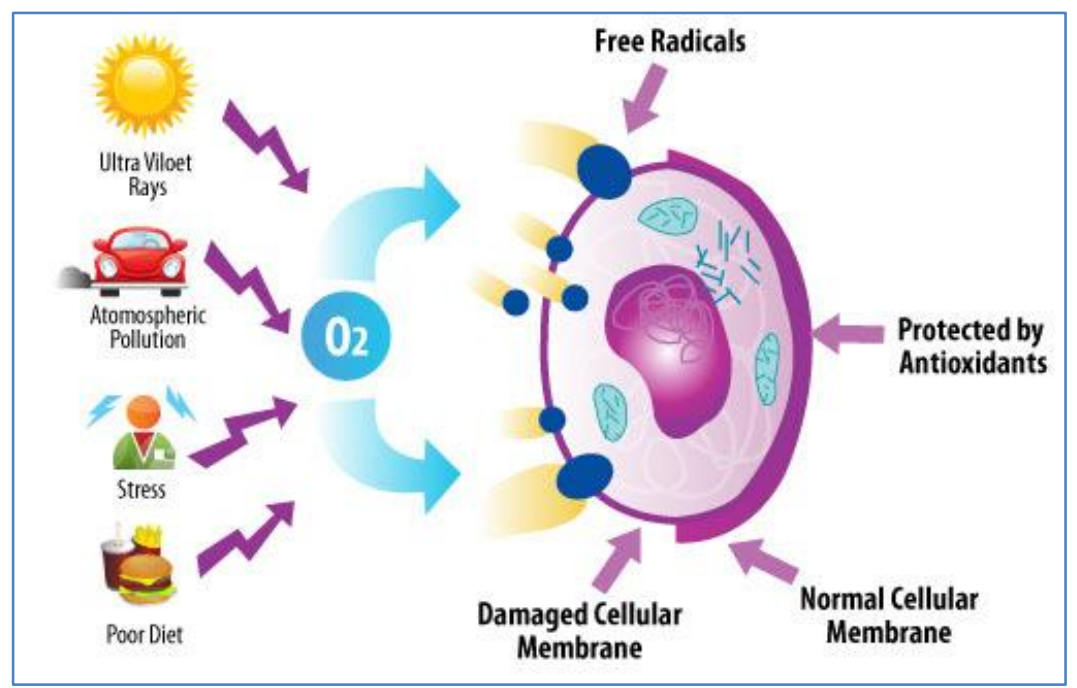

Fig-2: Shows the mechanism of free radicals in relation to cell membrane

\section{Role of Kaempferol as Antioxidant}

Kaempferol as one of the flavonoids that showing complexity structure and stable in nature. It also shoed relation to the different chemical compounds to due to its antioxidant properties. It was used in the cooking as well as for medical purposes. It contains the special structure that work against the cancer. Its main function involved in binding with cells of the cancer and ultimately kills the cancer cells. It also used as a source of the medicinal medicinal plant for the purpose to treat the diseases associated with cancer. It also binds to the cells of the heart and prevents the cells of the heart for the attack to cells of heart. It also reduces the high level of the pressure on the cells of the heart due to its antioxidant properties. The cellular level ultimately caused the formation of the free radicals due to the more level of oxidants in the specific cell. It has been acting high level of the antioxidants for the capturing of the free radicals that are produced due to the abnormal chemical reaction of the body. It then binds to the free radicals and final remove them from the body by no side effects to the cells of the body $[9,10]$.

There are certain gaps in literature about the different activities of the extracts of the onion. The antioxidant activity of the onion extract remains unclear and not completely studied yet. Different free radical leads to oxidative stress to the particular cell and ultimately causes the cancer. The further study needed to understand the nature of different chemical compounds in onion that responsible for antioxidant activity as well as for the different routes for entry of free radicals into the living[11].

Kaempferol acting the major flavonoid that has been medically used to treat the diseases of the heart. Normally, the cells of the heart need the proper supply of the gas namely nitrogen oxide. When these compounds properly reach to the cells of the heart, then heart performs its functions in such conditions that are associated with any of the normal conditions of the body. Nitrogen synthase works at the certain biological conditions then, nitrogen oxide not supplied to cells of the heart. This nitrogen oxide works in the presence of the enzyme called nitrogen oxide synthase that is effectively involved in the proper supply of the nitrogen oxide to the cells of the heart. If there more of the supply of the nitrogen synthase, then the cells of the heart not work and can undergo the condition called the death of the cells of the heart. All these conditions would be harmful to the functions of the cells of the heart when there more or less supply of the nitrogen oxide $[12,13]$.

\section{Role of Anthocyanin as Antioxidant}

Anthocyanin mainly the second type of the major compound in the outer portion of the skin of the onions that makes the colour of the onions bright when there large of the light usually the light when falls on the plants on the onions. Different studies were made on the different types of the onions depending of the colour and presence of the pigment such as the anthocyanin. The red type of the onions has the more of the concentrations of the anthocyanin and hence the colour of the red brighten. The skin of the onions also attracts the customers as wells the farmers in the marketing. The white type of the onions has the less of the concentrations of the anthocyanin and hence the colour of the onions of this type usually contains the darker. The last type of the onions has the normal concentrations of the anthocyanin and hence the colour of the red showing the activities against the free radicals depending on the type as well as the nature of the chemical compound [14].

The role of the anthocyanin in the metabolism effectively important to inhibit the free radicals that are produced abnormally and necessary to inhibit them in that termination of the reactions usually they started in the body. The cellular level as well as the molecular level ultimately causes the formation of the free radicals due to the more level of oxidants in the specific cell. 
Antioxidants, the major and effective source of flavonoids to inhibit the mechanism of the oxidants $[15,16]$. Then the anthocyanin acting in the reactions occurred for the formation of the compounds that important for the growth as well as removal of the toxic substances from the body as the product in the form of the waste. Anthocyanin in the onions as the flavonoids helping to lower the pressure that causes the veins of the blood to shrink as well as also leads to the provides the immunity to cells that acting as the natural booster with frightening the against the free radicals. They also remove the products from the oxidants from the body if remains in the body that ultimately leads to the toxicity [17].

\section{Role of Quercetin as anticancer}

Quercetin as the flavonoids that mandatory part of the food has been used in the past when it cultivated. This category of flavonoids that possess the several characteristics such fighting against the free radicals. It particularly involved to remove the free radicals that produced biochemically in the specific organ in order to keep as well as minimize the effects produced by the free radicals. Quercetin helps to prevent the cancer by attacking the free radicals that would attack on the normal cells and ultimately to the death of the many of the cells that are significant part of the body. It has many of functions in the body such inhibiting the free radicals as well as prevention of the cancer. It also reduces the stress faced by the cells of the blood such the RBCs. When there is more of the stress faced by the RBCs, then finally there is less supply of the oxygen to important part of the body such the lungs and due to less supply of the oxygen, death of the many tissues occurs finally. They attacked the cells of the body and overall all the reactions in the body would inhibit as well as blockages due to the chemicals such as the toxins that can be produced in the cells or can be produced outside of the cells [18].

Most of the toxins that produced by bacteria in the cells affected to the different parts of the body. Then, quercetin that present in highest concentration in the onions inhibit involved in the blockage as well as the growth at the initiation point when the bacteria as well as viruses enter in the body in a specific way. The high concentration of quercetin leads to less growth of the bacteria as well as viruses [19].

Most of the studies provide evidences about two types of the quercetin that found in the inner position of the onions. The presence of these two types of chemical compounds significantly reduced the entrance of the free radicals by binding as well as removing from the body. The first type of the quercetin 3,4 -O-beta-diglycopyranoside that actually formed when quercetin combines with glycosides in the specific positions and ring like and heavy structure is obtained that is effective blockage the oxidants as well the free radicals. When quercetin combines with glycosides in the specific positions and ring like and heavy structure obtained that particularly effective for blocking the oxidants as well as the free radicals. When both of these types taken from the onions, less chances of the free radicals to attack the body and hence less of the damage caused by free radicals due to high concentrations of the flavonoids[20].

The free radicals also inhibited the electrons in the metabolic events that occured in the formation of the useful and variety of the lipids. But the oxidants attack on the cells of the lipids and disturbed the membrane of the cell by taking the electrons that involved in the formation of the formation of the proteins in combinations with lipids that categorized as the conjugated to perform the functions of the cells effectively. The antioxidants also helpful in regulating biochemically the events occurring during the formation of anabolism as well as catabolism. The major type of antioxidants that showed activity against free radicals by blocking them when attack occurs on the membrane of the cell. Higher of the concentrations of the flavonoids like quercetin, less the attacked of the free radicals that blocked initially by treatments with onions taken through the $\operatorname{diet}[21,22]$.

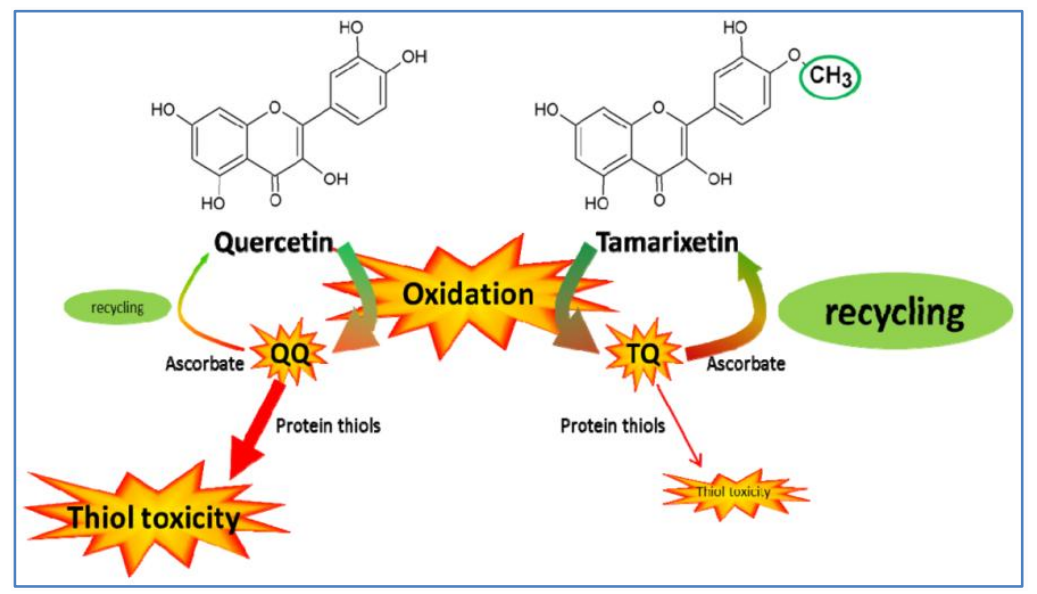

Fig-3: Shows the role of quercetin with free radicals 
Quercetin as the antioxidant playing important role in making the important composition of the onions helps to reduce the lipids peroxidation by removing the free radicals that are attached to the specific chain of the lipids. It also important to inhibit these free radicals at the starting of the chain because once these attached then difficult to remove them. These radicals then started the chain the ultimately inhibited the overall reactions of the synthesis of the lipids. Less formation of the lipids occurred in the cells of the brain then the sheath of the brain that made of the lipids also disturbed. As ultimately leads to attacked to the cells of the brain once the injury occurs. It also causes if the damages to membranes of the cell that actually most of the lipids that playing important role in overall the process occurring in the body. The formation of the ketone also dependent on the formation of the lipids because moreo formation of lipids leads to of the formation of the ketone in the body. If there is high concentrations of the lipid there no of the more of the formation of the ketone in the body[23,24,25].

Quercetin also involved in the lowering the risks of the diseases majorly associated with cancer as well as heart[26,27]. The antioxidants posses with a certain properties that differentiated them to the other members of the other compounds found and active in the onion. The cells of the heart attacked by the free radicals that involved in the oxidation of the lipids[28]. Once the layer of the lipids in heart deposited mistakenly more of the lipids accumulated in the outer layer of the heart and ultimately damaged it at the alarming and most of the patients suffered from the attacked to the heart and then finally death of the in these patients are severally occurred[29,30]. Lipids in the one way has benefit to the membrane of the brains by protecting them injuries as well as severe attack while in most of severe types of the cases of the deaths occurred due to more of the lipids in the outer layer of the cells and causes the global issues in the world[31].

A food is something that provides nutrients. Nutrients are substances that provide energy for activity, growth, and all functions of the body such as breathing, digesting food, and keeping warm; materials for the growth and repair of the body, and for keeping the immune system healthy [32-34]. Every cell in the body depends on a continuous supply of calories and nutrients, whether obtained through food, IV nutrients, or tube feedings. Eating and food, however, also have symbolic meanings associated with love, sensuality, comfort, stress reduction, security, reward, and power [35].

\section{CONCLUSION}

The free radicals also inhibited the electrons in the metabolic events that occured in the formation of the useful and variety of the lipids. Kaempferol acting the major flavonoid that have been medically used to treat the diseases of the heart. Quercetin as the valuable type of the flavonoids that have been used in the purpose of the preventing diseases associated with the bacteria as well as the viruses. It becomes difficult to stop the growth of the bacteria as well as viruses when these enter into the body.

\section{REFERENCES}

1. Usman, G., Muhammad, N., Hamza, R., Usman, I., Ayesha, A., Saqib, U., ... \& Fatima, Q. (2019). A Novel Approach towards Nutraceuticals and Biomedical Applications. Scholars International Journal of Biochemistry, 2(10), 245-252.

2. Shahidi, F. (2000). Antioxidants in food and food antioxidants. Food/nahrung, 44(3), 158-163.

3. Namiki, M. (1990). Antioxidants/antimutagens in food. Critical Reviews in Food Science \& Nutrition, 29(4), 273-300.

4. Pokorný, J., Yanishlieva, N., \& Gordon, M. (Eds.). (2001). Antioxidants in food: practical applications. Elsevier.

5. Rajalakshmi, D., \& Narasimhan, S. (1995). Food antioxidants: sources and methods of evaluation. FOOD SCIENCE AND TECHNOLOGY-NEW YORK-MARCEL DEKKER-, 65-158.

6. Cömert, E. D., \& Gökmen, V. (2018). Evolution of food antioxidants as a core topic of food science for a century. Food Research International, 105, 7693.

7. Carocho, M., Morales, P., \& Ferreira, I. C. (2018). Antioxidants: Reviewing the chemistry, food applications, legislation and role as preservatives. Trends in Food Science \& Technology, 71, 107-120.

8. Nirmala, C., Bisht, M. S., Bajwa, H. K., \& Santosh, O. (2018). Bamboo: A rich source of natural antioxidants and its applications in the food and pharmaceutical industry. Trends in Food Science \& Technology, 77, 91-99.

9. Grzesik, M., Naparło, K., Bartosz, G., \& Sadowska-Bartosz, I. (2018). Antioxidant properties of catechins: Comparison with other antioxidants. Food chemistry, 241, 480-492.

10. Ozkan, G., Franco, P., De Marco, I., Xiao, J., \& Capanoglu, E. (2019). A review of microencapsulation methods for food antioxidants: Principles, advantages, drawbacks and applications. Food chemistry, 272, 494-506.

11. Ahsan, M., Aslam, M., Akhtar, M. A., Azmi, U. R., Naeem, M., Murtaza, G., ... \& Shafiq, S. (2019). Effect of inoculation of three rhizobial strains on maize hybrids. Journal of Biodiversity and Environmental Sciences, 14(6), 168-177.

12. Naeem, A., Saddique, S., \& Chand, S. A. (2019). Advancement and Future Directions towards Herbal Treatment for Various Diseases.

13. Naeem, M., Hussain, A., Azmi, U. R., Maqsood, S., Imtiaz, U., Ali, H., ... \& Ghani, U. (2019). Comparative Anatomical Studies of Epidermis with Different Stomatal Patterns in Some Selected 
Plants Using Compound Light Microscopy. International Journal of Scientific and Research Publications, 9(10), 375-380.

14. Naeem, M., Ashraf, A., Safdar, H. M. Z., Khan, M. Q., Rehman, S. U., Iqbal, R., ... \& Ahmad, G. Biochemical changes in patients with chronic kidney failure in relation to complete blood count and anemia.

15. Hussain, A., Rafeeq, H., Asghar, A., Ullah, S., Imtiaz, U., Ullah, H., ... \&amp;amp; Ilyas, M. D. Combined inhibitory potential of Ammonium thiosulphate and 2-chloro- (trichloromethyl) pyridine on ureases activities.

16. Muhammad Naeem, Muhammad Mujahid, Asim Umer, Siraj Ahmad, Ghafoor Ahmad, Jabir Ali, Sayed Jasim Raza Zaidi, Muhammad Zohaib Hassan, Tania Zaheer, Irfan Khalid. New trends in removing toxic metals from drinking and wastewater by biomass materials and advanced membrane technologies. J. Bio. Env. Sci. 15(3), 1017, September 2019.

17. Rafeeq, H., Arshad, M. A., Amjad, S. F., Ullah, M. H., Muhammad, H., Imran, R. K., ... \&amp;amp; Ajmal, H. Effect of Nickel on Different Physiological Parameters of Raphanus Sativus.

18. Rafeeq, H., Tanvir, K., Khan, M. A. B., Basit, I., U1, Q., Ain, F. F., ... \&amp;amp; Siddique, S. An Effective Approach towards Heavy Metals and their Effects on Different Organs of the Body.

19. Asim Hussain, Naima Nashat, Ayesha Liaqat, Misbah Waheed, Maryam Aslam, Nida Asif. 2020. A Comprehensive Review on Diabetic Retinopathy and Mental Disorders. IOSR Journal of Biotechnology and Biochemistry. Volume 6, Issue 3 , PP 38-51. 2

20. Salman Maqsood, Saba Qadir, Asim Hussain, Asma Asghar, Rubab Saleem, Sara Zaheer, Noman Nayyar. 2020. Antifungal Properties of Copper Nanoparticles against Aspergillus niger. Scholars International Journal of Biochemistry, April 2020; 3(4): 87-91.

21. Ahmad, I., Khan, S., Naeem, M., Hayat, M., Azmi, U. R., Ahmed, S., \& Irfan, M. (2019). Molecular Identification of Ten Palm Species using DNA Fingerprinting. Int. J. Pure App. Biosci, 7(1), 4651.

22. Hamza, R., Irha, B., Rizwana, J., Iqra, S., Kanwal, S., Sobia, T., Qurat, ul Ain Naseer., Hafiza Mariyem, R. (2020). Biochemistry of Water Soluble Vitamins, Sources, Biochemical Functions and Toxicity. Scholars International Journal of Biochemistry.

23. Rafeeq, H., Ahmad, S., Tareen, M. B. K., Shahzad, K. A., Bashir, A., Jabeen, R., \& Shehzadi, I. Biochemistry of Fat Soluble Vitamins, Sources, Biochemical Functions and Toxicity.

24. Naeem, M., Ali, J., Hassan, M. Z., Arshad, B., Rao, M. H. I., Sarmad, M. S. K., ... \& Hussain, M. U.
Novel Approach towards DNA Barcoding as a Tool in Molecular Biology and Biological Activities of Cyclotides with Particular Emphasizes at Molecular Level.

25. Dodeigne, C., Thunus, L., \& Lejeune, R. (2000). Chemiluminescence as diagnostic tool. A review. Talanta, 51(3), 415-439.

26. Shafiq, S., Adeel, M., Raza, H., Iqbal, R., Ahmad, Z., Naeem, M., \& Azmi, U. R. (2019). Effects of Foliar Application of Selenium in Maize (Zea Mays L.) under Cadmium Toxicity. In Biological Forum-An International Journal, 11(2), 27-37.

27. Naeem, M., Hayat, M., Qamar, S. A., Mehmood, T., Munir, A., Ahmad, G., \& Hussain, A. (2019). Risk factors, genetic mutations and prevention of breast cancer. Int. J. Biosci, 14(4), 492-496.

28. Serafini, M., Bugianesi, R., Maiani, G., Valtuena, S., De Santis, S., \& Crozier, A. (2003). Plasma antioxidants from chocolate. Nature, 424(6952), 1013-1013.

29. Abdel-Daim, M. M., El-Tawil, O. S., Bungau, S. G., \& Atanasov, A. G. (2019). Applications of antioxidants in metabolic disorders and degenerative diseases: Mechanistic approach. Oxidative Medicine and Cellular Longevity, 2019.

30. Gremski, L. A., Coelho, A. L. K., Santos, J. S., Daguer, H., Molognoni, L., do Prado-Silva, L., \& Azevedo, L. (2019). Antioxidants-rich ice cream containing herbal extracts and fructooligossaccharides: manufacture, functional and sensory properties. Food chemistry, 298, 125098.

31. Hęś, M., Dziedzic, K., Górecka, D., JędrusekGolińska, A., \& Gujska, E. (2019). Aloe vera (L.) Webb. Natural Sources of Antioxidants-A Review. Plant Foods for Human Nutrition, 1-11.

32. Amarowicz, R., \& Pegg, R. B. (2019). Natural antioxidants of plant origin. In Advances in food and nutrition research; 90: 1-81). Academic Press.

33. Agregán, R., Barba, F. J., Gavahian, M., Franco, D., Khaneghah, A. M., Carballo, J., \& Lorenzo, J. M. (2019). Fucus vesiculosus extracts as natural antioxidants for improvement of physicochemical properties and shelf life of pork patties formulated with oleogels. Journal of the Science of Food and Agriculture, 99(10), 4561-4570.

34. Călinoiu, L. F., Cătoi, A. F., \& Vodnar, D. C. (2019). Solid-state yeast fermented wheat and oat bran as a route for delivery of antioxidants. Antioxidants, 8(9), 372.

35. Shi, S., Guo, K., Tong, R., Liu, Y., Tong, C., \& Peng, M. (2019). Online extraction-HPLC-FRAP system for direct identification of antioxidants from solid Du-zhong brick tea. Food chemistry, 288, 215-220. 